\title{
The Effect of A100 Gel, on Hair Growth and Hair Quality: An Explanatory Study
}

\author{
Jan Faergemann ${ }^{1 *}$, Thomas Hedner ${ }^{2}$ \\ ${ }^{1}$ Department of Dermatology, Sahlgrenska University Hospital, Gothenburg, Sweden \\ ${ }^{2}$ Department of Clinical Pharmacology, Sahlgrenska University Hospital, Gothenburg, Sweden \\ Email: "jan.faergemann@derm.gu.se
}

Received 24 January 2016; accepted 7 March 2016; published 10 March 2016

Copyright (C) 2016 by authors and Scientific Research Publishing Inc.

This work is licensed under the Creative Commons Attribution International License (CC BY). http://creativecommons.org/licenses/by/4.0/

(c) (i) Open Access

\begin{abstract}
Male pattern baldness or androgenic alopecia is a great problem for many individuals' especially young people. A100 is composed of two active ingredients, a pollen extract and pentane-1,5-diol. The pollen extract provides a source of natural nutrients and pentane-1,5-diol acts as a solvent to unplug the hair follicle as well as acts as an enhancer for uptake of nutrients. Other components are claimed to increase blood flow to the hair papilla. A100 has been effective in earlier studies. The aim of this open explanatory study was to investigate the effect of 4 months twice daily application with this commercial pollen gel, $\mathrm{A100}$, in subjects with male androgenic alopecia. Twenty male subjects, between 18 and 40 years with androgenic alopecia were included. A100 gel was applied to the area of the scalp with poor hair growth twice daily for 4 months. The subjects were seen at the start of treatment and then every month. Sixteen subjects fulfilled the whole 4 months of treatment and 2 fulfilled 3 months of treatment. A statistically significant increase in number of hairs was seen after 4 months of treatment with $\mathrm{A100}(\mathrm{p}<0.001)$. This effect was seen for all types of hair. Fifty-six percent of the 16 subjects who fulfilled the 4 months treatment had an increase in hair growth of more than $50 \%$, and $31 \%$ had an increase over $100 \%$. No side effects were seen and the subjects found $\mathbf{A 1 0 0}$ gel a cosmetically attractive treatment. A100 was in this explanatory study an effective and safe treatment for androgenic alopecia or male pattern baldness.
\end{abstract}

\section{Keywords}

Pollen Extract, Pentane-1,5-Diol, Explanatory, Androgenic Alopecia

\section{Introduction}

Reduced growth and quality of scalp hair are a problem for many people and are often caused by androgenic alopecia [1]-[3]. This condition affects both men and women but onset occurs much earlier in men, often be${ }^{*}$ Corresponding author.

How to cite this paper: Faergemann, J. and Hedner, T. (2016) The Effect of A100 Gel, on Hair Growth and Hair Quality: An Explanatory Study. Journal of Cosmetics, Dermatological Sciences and Applications, 6, 19-23. 
tween the ages of 20 and 30. Women are also affected with the first signs occurring closer to the age of 40 with a higher frequency after menopause. It can have a big impact on a person's confidence, identity and relationships and therefore new treatments for hair loss are greatly sought after. Today two drugs, minoxidil and finastererid are approved for medical treatment of androgenic alopecia [4]-[8].

A100 is a gel containing an extract of a lipophilic pollen extract in a gel vehicle. The gel also contains Aloe Vera, vitamin E, zinc chloride, zinc oxide and biotin. The gel base contains compounds commonly used in gel formulations. Pentane-1,5-diol is added as a solvent and enhancer [9]. The gel has been developed by Natumin Pharma, Habo, Sweden. In case reports from China and India A100 gel improved hair growth and hair quality and no adverse events were reported. The pollen is grown in southern Sweden and during the pollen extraction process the allergens are removed from the pollen and the resulting extract is deemed to be free from allergens. No adverse events have been reported during use of this product.

The aim of the present study was to investigate the effect of A100 gel on hair growth measured by an increase in the growth rate of the hair during treatment. The following secondary variables will also be considered: An increase in the quality of the hair is measured by an increase in intermediate and terminal hairs during treatment.

\section{Methods}

\subsection{Study Population}

Twenty male subjects between 18 and 40 years with androgenic alopecia were included. They were enrolled through an advertisement in the local newspaper.

\subsection{Study Design}

This study was performed as a single-centre, open, explanatory study on the effect of A100 gel on hair growth and hair quality in subjects with a reduced hair growth and a reduced hair quality. The study period was 4 months with follow-up visits every month. Subjects who fulfil the inclusion and exclusion criteria at the first visit were given A100 gel to be used on the scalp, in the area with decreased hair growth and with hair of poor quality, twice daily. The total daily amount was $0.5 \mathrm{ml}$ twice daily. A neutral shampoo (i.e. a shampoo considered not to be therapeutically active) was provided to the subjects. No other shampoo or hair styling formulations were allowed. The inclusion criteria were: males 18 - 40 years, slow growing hair of poor quality and written informed consent. The exclusion criteria were: Evidence of severe organic disease or dermatological disease as revealed by history, physical examination and laboratory assessments which may interfere with the administration or assessment of study medication. Current use of dermatological drugs/preparations which may interfere with the study evaluation, intolerance to the ingredients in the formulations or previous inclusion in this study. Current alcohol or drug abuse or any other condition associated with poor compliance or treatment with any investigational drug within the four weeks prior to entering the study.

\subsection{Efficacy Assessment}

At the first visit the area in which the hair were slow growing and of poor quality was selected. A $2.5 \mathrm{~cm}$ diameter test area, within this area was selected using a plastic template. This area was carefully measured to be in the same location at each visit using the tops of the ears, the base of the nose and the eyebrows as landmarks. At the first visit the length of the hair in the area was trimmed to a length of $1 \mathrm{~cm}$. The number of hair was counted and the hair was classified as vellus, intermediate and terminal. This classification is an indication of hair quality. Digital photos were taken. At each follow up visits the length of the hair was measured. All other procedures were the same as in the first visit.

\subsection{Safety Assessments}

Adverse events were recorded from the start of the first treatment period to the end of the study. At each study visit, investigators asked patients the following question: "have you had any health problems since your last visit?”. The Investigator rated any reported events for intensity and relationship to study treatment.

\subsection{Statistical Analysis}

Wilcoxon's signed rank test was used to describe the changes in number of total hair, terminal hair, intermediate 
hair and vellus hair between baseline and end of treatment.

\section{Results}

\subsection{Patient Disposition}

Sixteen subjects fulfilled the whole 4 months of treatment. One subject never returned for any follow up. One subject stopped after 2 months of treatment and 2 subjects stopped after 3 months of treatment because they were not able to fulfil the treatment for practical reasons.

\subsection{Efficacy Results}

There was a statistically significant increase in numbers of hair after 4 months of treatment (Table 1) and this effect was seen for all 3 types of hair. Fifty six percent (9 subjects) of the 16 subjects who fulfilled the whole 4 months treatment had an increase in hair growth of more than 50\%, and 31\% had an increase over $100 \%$.

\subsection{Safety and Tolerability}

No side effects were seen and the subjects found A100 gel a cosmetically attractive treatment.

\section{Discussion}

Today topical applied minoxidil and oral finasterid are approved for the treatment of androgenic alopecia in men and topical minoxidil also in women [4]-[7]. Minoxidil is approved in several countries as a topical formulation for the stimulation of hair growth in men and even for a reduction in hair loss. Minoxidil is a piperedinpyrimidin derivative. The exact mechanism of action of topical applied minoxidil is unknown. However, one hypothesis is that it may increase blood flow to hair follicles in the scalp. It has to be applied twice daily for 3 to 4 months before any effect can be seen. An acceptable stimulation of hair growth has been reported in approximately $32 \%$ to $48 \%$ of the subjects [4] [5].

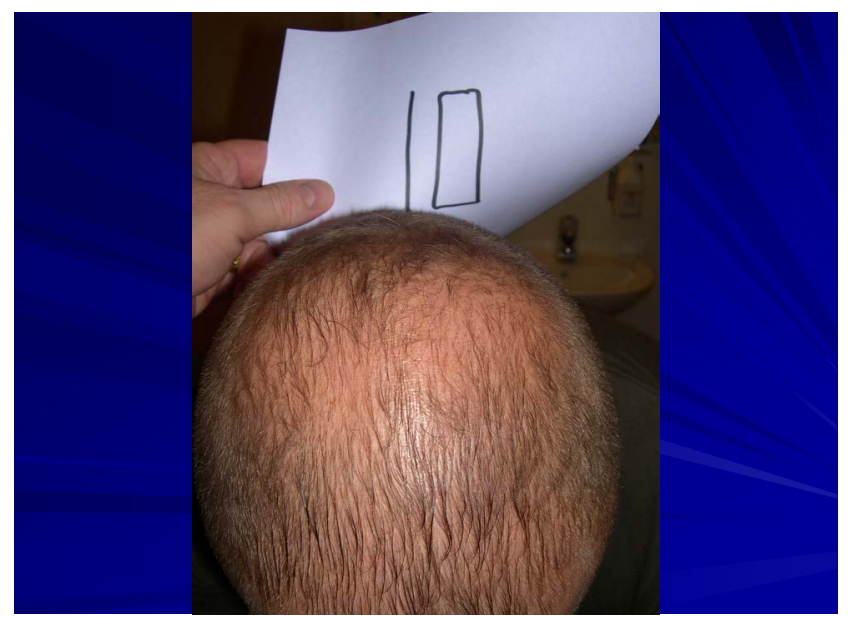

Figure 1. A subject with male pattern baldness before treatment with A100 gel.

Table 1. Increase in numbers of hair after 4 months treatment with A100 gel.

\begin{tabular}{cccc}
\hline & $\begin{array}{c}\text { Before treatment } \\
(\text { mean) }\end{array}$ & $\begin{array}{c}\text { After 4 months of } \\
\text { treatment (mean) }\end{array}$ & P-value \\
\hline Total no. of hair & 41 & 70 & $<0.0001$ \\
Terminal hair & 37 & 55 & 0.0003 \\
Intermediate hair & 1 & 6 & $<0.0001$ \\
Vellus hair & 3 & 10 & 0.0002 \\
\hline
\end{tabular}




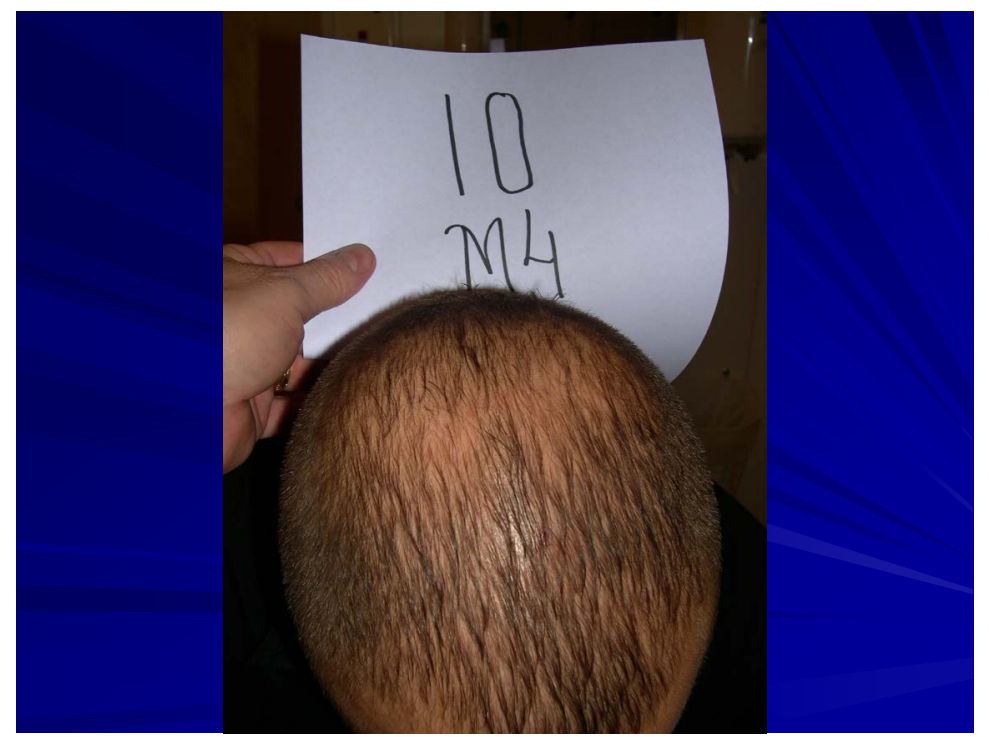

Figure 2. The same subject after 4 months treatment with A100 gel twice daily.

Finasterid is approved in several countries as an oral treatment for the stimulation of hair growth in men with androgenic alopecia [6] [7]. It is a 4-azasteroid with an inhibitory effect on human 2, $5 \alpha$-reductase with more than 100 times higher selectivity compared to human type 1, $5 \alpha$-reductase and blocks the peripheral conversion of testosterone to androgen dihydro testosterone (DHT). In men with androgen alopecia there is a decrease in the size of the hair follicles and an increase in DHT. Finasterid has an inhibitory effect on the process that leads to a reduction in the size of hair follicles. In several studies finasterid had a stimulatory effect on hair growth with the appearance of new hair in $14 \%$ to $16 \%$ and only $17 \%$ of subjects treated for 24 months had sign of hair loss compared to $72 \%$ in the placebo group [6] [7].

Although mostly safe some side effects have been reported with the use of the two drugs. With minoxidil irritant and allergic skin reactions have been reported [4] [5]. With finasterid reduced libido, reduced ejaculate volume and mental depression have been reported [6]-[8].

In this explanatory study A100 gel showed increased hair growth in over $50 \%$ of the treated subjects and no side effects were reported. The exact mode of action of A100 gel is unknown but nutrient supply to the hair root provided by the actions of pentane-1,5-diol is one hypothesis (Figure 1, Figure 2).

This explanatory study indicated that A100 gel has a stimulatory effect on hair growth with no reported side effects. Further, larger and controlled trials are necessary to prove the efficacy of A100 gel.

\section{References}

[1] Dawber, R.P.R., de Berker, D. and Wojnarowska, F. (1998) Alopecia Ch 66, Disorders of Hair. In Rook/Wilkinsson/ Ebling, Eds. In: Champion, R.H., Burton, J.L., Burns, D.A. and Breathnach, S.M., Eds., Textbook of Dermatology, Vol. 4, 6th Edition, Blackwell Science Publ., Oxford, 2903-2909.

[2] Rushton, D.H. (1999) Androgenetic Alopecia in Men: The Scale of the Problem and Prospects for Treatment. International Journal of Clinical Practice, 53, 50-53.

[3] Hamilton, J.B. (1951) Patterned Loss of Hair in Man: Types and Incidence. American Journal of New York Academy of Sciences, 53, 708-728. http://dx.doi.org/10.1111/j.1749-6632.1951.tb31971.x

[4] Koperski, J.A., Orenberg, E.K. and Wilkinson, D.I. (1987) Topical Minoxidil Therapy for Androgenetic Alopecia. Archives of Dermatology, 123, 1483-1487. http://dx.doi.org/10.1001/archderm.1987.01660350083018

[5] Rietschel, R.L. and Duncan, S.H. (1987) Safety and Efficacy of Topical Minoxidil in the Management of Androgenetic Alopecia. Journal of the American Academy of Dermatology, 16, 677-685. http://dx.doi.org/10.1016/S0190-9622(87)70087-5

[6] Finasteride Male Pattern Hair Loss Study Group (2002) Long-Term (5-Year) Multinational Experience with Finasteride $1 \mathrm{mg}$ in the Treatment of Men with Androgenetic Alopecia. European Journal of Dermatology, 12, 38-49.

[7] Whiting, D.A., Olsen, E.A., Savin, R., Halper, L., Rodgers, A., Wang, L., Hustad, C. and Palmisano, D. (2002) Effi- 
cacy and Tolerability of Finasteride $1 \mathrm{mg}$ in Men Aged 41 to 60 Years with Male Pattern Hair Loss. European Journal of Dermatology, 13, 150-160.

[8] Altomare, G. and Capella, G.L. (2002) Depression Circumstantially Related to the Administration of Finasteride in Androgenic Alopecia. Journal of Dermatology, 29, 665-669. http://dx.doi.org/10.1111/j.1346-8138.2002.tb00200.x

[9] Sundberg, J.J. and Faergemann, J. (2008) A Comparison of Pentane-1,5-Diol to Other Diols for Use in Dermatology. Expert Opinion for Investigative Drugs, 17, 601-610. http://dx.doi.org/10.1517/13543784.17.4.601 